\title{
COVID-19 and ethics in the ICU
}

\author{
Sarah E. Nelson
}

The COVID-19 pandemic has brought into focus many medical ethics questions; several have burdened intensive care unit physicians in particular (Fig. 1). The aim of this article is to provide a frank yet thoughtful discussion of the many facets of these ethical dilemmas.

We intensivists potentially put ourselves at risk each time we report to work. This is scary and unsettling. Hundreds of years ago, physicians had no professional or ethical obligation to take care of sick patients during disease outbreaks, some purposely fleeing from plagueridden areas [1]. However, times have changed. Most medical students now recite the Hippocratic Oath, which states that: "I will apply, for the benefit of the sick, all measures [that] are required," though nowhere does it state that physicians must work in settings that could put their own health at risk [2]. Following the events of September 11, 2001, the American Medical Association (AMA) reaffirmed their stance that "it is a responsibility of health professionals to continue caring for patients even if doing so presents some danger to them" [1]. This includes an "obligation to provide urgent medical care during disasters ... even in the face of greater than usual risks to physicians' own safety, health, or life." Given the large scope of the pandemic and the deadliness of SARS-CoV-2, these statements may not adequately address this ethical quandary. For instance, it is not entirely clear how much of a hazard is actually acceptable. And risk to healthcare workers is real: $>3300$ were infected in China as of early March 2020 as were $20 \%$ of healthcare workers in Italy [3]; hundreds of these workers around the world have died since the pandemic began [4]. Healthcare providers may feel they did not sign up for their jobs knowing that they may need to sacrifice themselves for others [5]. In addition, hospitals have periodically suffered from shortages of personal

Correspondence: senelson13@gmail.com

Departments of Neurology and Anesthesiology \& Critical Care Medicine, Johns Hopkins University, 600 N Wolfe Street, Phipps 455, Baltimore, MD 21287, USA

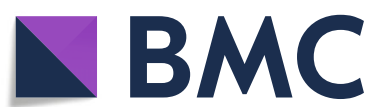

protective equipment (PPE). Is it ethical to ask intensivists and other healthcare providers to counter this contagious threat with inadequate battle gear?

One of the most upsetting issues of the pandemic is the limited number of critical care resources, including ventilators and intensive care unit beds, available to COVID-19 patients and other critically ill patients. In countries such as Italy, healthcare providers have had to make difficult decisions about who is provided a ventilator and who is not and thus forced to dictate life and death [6], and other countries have prepared to face similar difficult decisions. In what almost seems a foreshadowing, distribution of limited resources was explored recently by a Johns Hopkins intensivist and her team. Participants in the study felt that, in times of crisis, shortand long-term outcomes should be primarily considered (versus a lottery system or first come, first served) in deciding who should be prioritized to receive scarce resources [7]. The same research group then generated a framework based on the 2 major ethical considerations they had identified: short-term survival, with the support of all available resources, and long-term survival, with consideration of comorbidities [8].

Specific to the COVID-19 pandemic, 4 ethical guiding principles to consider when resources are limited have been noted: (1) maximizing benefits of scarce resources, (2) treating all people equally, (3) preferentially selecting those with instrumental value, and (4) prioritizing patients who are worst off [9]. Based on these principles, 6 recommendations have been made for the current outbreak: maximizing benefits including using scarce resources responsibly and saving more lives/years of life, prioritizing COVID-19 resources (i.e., PPE, vaccines) to healthcare workers, invoking equality using random allocation or lottery to distribute resources to those with similar prognoses, thoughtful consideration of resource allocation (e.g., prioritizing older patients, among the most affected by SARS-CoV-2, to receive a vaccine), prioritizing those who have participated in COVID-19-related

(c) The Author(s). 2020 Open Access This article is licensed under a Creative Commons Attribution 4.0 International License, which permits use, sharing, adaptation, distribution and reproduction in any medium or format, as long as you give appropriate credit to the original author(s) and the source, provide a link to the Creative Commons licence, and indicate if changes were made. The images or other third party material in this article are included in the article's Creative Commons licence, unless indicated otherwise in a credit line to the material. If material is not included in the article's Creative Commons licence and your intended use is not permitted by statutory regulation or exceeds the permitted use, you will need to obtain permission directly from the copyright holder. To view a copy of this licence, visit http://creativecommons.org/licenses/by/4.0/. The Creative Commons Public Domain Dedication waiver (http://creativecommons.org/publicdomain/zero/1.0/) applies to the data made available in this article, unless otherwise stated in a credit line to the data. 


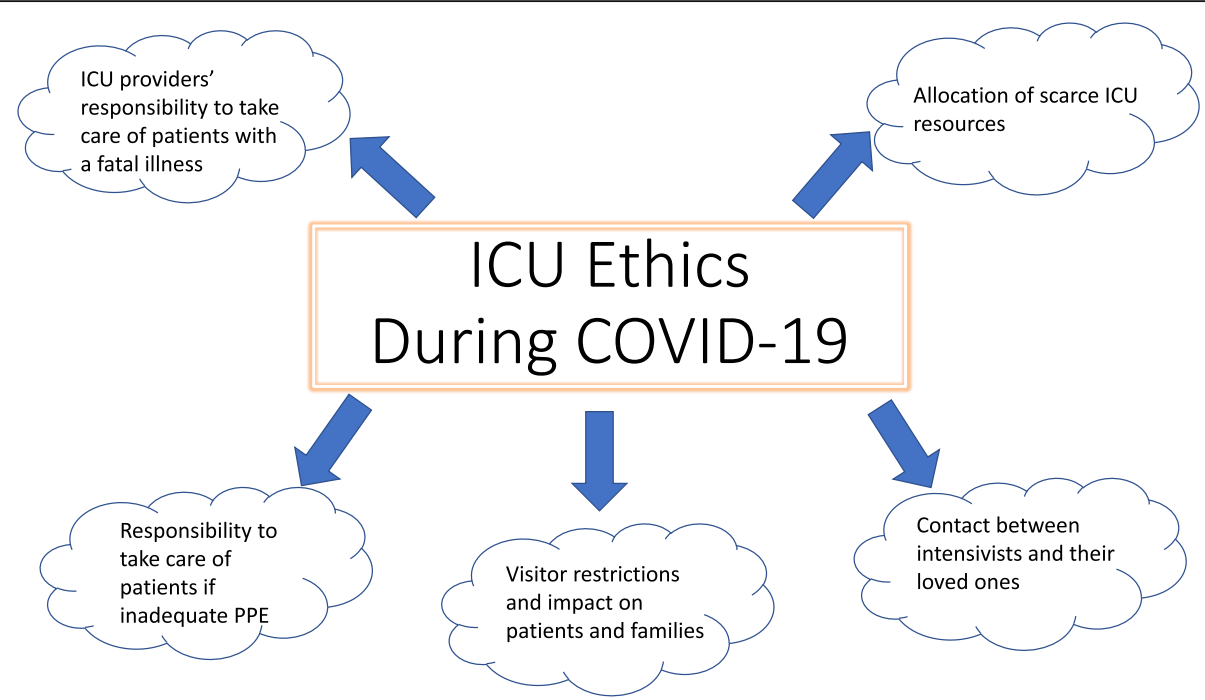

Fig. 1 Medical ethics issues encountered by intensivists during the COVID-19 pandemic

research, and providing equal resources to those with COVID-19 and those with other medical conditions [9].

In response to the pandemic, The Johns Hopkins Hospital convened a Scare Resource Taskforce to reach a consensus about available resources in Maryland and triggers for initiating a framework requiring allocation of scarce resources. Other US states have formally approved a scare resource allocation protocol, and individual medical centers have been forced to put together such polices or released recommendations regarding issues to consider when designing them $[10,11]$. One of the most severely afflicted epicenters in the world, New York State has instituted legal immunity for physicians forced to make these difficult triage decisions. Given the increasing number of COVID-19 cases, the potential need to triage critical care resources has deeply affected physicians [12].

Further, visitor restrictions in hospitals have led to emotionally painful experiences. Visitors can augment patient histories and provide sources of comfort to patients. Unfortunately, by increasing the number of people in a hospital at one time, hospital visitors can potentially hamper social distancing and contribute to increased spread of SARS-CoV-2. As a result, many hospitals have closed their doors to visitors except under special circumstances. In one of the more heartbreaking aspects of this crisis, many patients have therefore died alone and without loved ones at their bedside [13]. Inpatients admitted for other reasons have also been affected and unable to communicate with their families in person [14].

Another ethical dilemma exists at home. What level of interaction after a day at work is safe between healthcare providers caring for COVID-19 patients and their families? While essential workers wish to sustain their personal relationships, their interactions with other people after working in the hospital could possibly increase spread of SARS-CoV-2 and cause additional suffering. Many physicians have struggled with this quandary [15]. In a similar vein, large family gatherings including weddings and funerals have been impacted and thus forced to downsize, which has also created great distress.

Several ethical dilemmas associated with the COVID-19 pandemic affect intensive care physicians. No one yet knows the full extent of the psychological injury that these issues have caused, but unfortunately it will likely be significant.

\section{Acknowledgements}

None.

Author's contributions

S.E.N. designed the topic of the paper, collected the data, wrote the first and final drafts of the manuscript, and critically revised the paper. The author read and approved the final manuscript.

\section{Funding}

None.

Availability of data and materials Upon request.

Ethics approval and consent to participate N/A

Consent for publication Yes.

Competing interests None. 
Received: 6 August 2020 Accepted: 12 August 2020

\section{Published online: 25 August 2020}

\section{References}

1. Smith TM. Doctors obliged to provide pandemic care. It wasn't always that way [online]. American Medical Association, https://www.ama-assn.org/ delivering-care/public-health/doctors-obliged-provide-pandemic-care-itwasn-t-always-way; 2020 [accessed 28 Mar 2020].

2. Tyson P. The hippocratic oath today [online]. PBS, https://www.pbs.org/ wgbh/nova/article/hippocratic-oath-today/; 2001 [accessed 28 Mar 2020].

3. The Lancet. COVID-19: protecting health-care workers. The Lancet. 2020; 395:922.

4. In Memoriam: Healthcare workers who have died of COVID-19 [online]. Medscape, https://www.medscape.com/viewarticle/927976; 2020 [accessed 30 Apr 2020].

5. Anonymous. Physicians are disposable and are taken for granted [online]. KevinMD.com, https://www.kevinmd.com/blog/2020/03/physicians-aredisposable-and-are-taken-for-granted.html; 2020 [accessed 28 Mar 2020].

6. Rosenbaum L. Facing Covid-19 in Italy - ethics, logistics, and therapeutics on the epidemic's front line. N Engl J Med. 2020;382:1873-5.

7. Biddison ELD, Gwon HS, Schoch-Spana M, et al. Scarce resource allocation during disasters: a mixed-method community engagement study. Chest. 2018;153:187-95.

8. Daugherty Biddison EL, Faden R, Gwon HS, et al. Too many patients ... a framework to guide statewide allocation of scarce mechanical ventilation during disasters. Chest. 2019;155:848-54

9. Emanuel EJ, Persad G, Upshur R, et al. Fair allocation of scarce medical resources in the time of Covid-19. N Engl J Med. 2020;382:2049-55.

10. Truog RD, Mitchell C, Daley GQ. The toughest triage - allocating ventilators in a pandemic. N Engl J Med. 2020;382:1973-5.

11. Feinstein MM, Diforatos JD, Hyun I, et al. Considerations for ventilator triage during the COVID-19 pandemic. Lancet Respir. 2020:8:e53.

12. Senior J. The psychological trauma that awaits our doctors and nurses [online]. The New York Times, https://www.nytimes.com/2020/ 03/29/opinion/coronavirus-ventilators-rationing-triage.html; 2020 [accessed 2 Apr 2020].

13. Wakam GK, Montgomery JR, Biesterveld BE, Brown CS. Not dying alone - modern compassionate care in the Covid-19 pandemic. N Engl J Med. 2020;382:e88.

14. Lamas DJ. I'm on the front lines. I have no plan for this. [online]. The New York Times, https://www.nytimes.com/2020/03/24/opinion/coronavirushospital-visits.html; 2020 [accessed 28 Mar 2020].

15. Rose C, Am I. Part of the cure or am I part of the disease? Keeping coronavirus out when a doctor comes home. N Engl J Med. 2020;382:1684-5.

\section{Publisher's Note}

Springer Nature remains neutral with regard to jurisdictional claims in published maps and institutional affiliations. 